concept analogous to exposure, so measurements must be expressed either in terms of fundamental quantities such as fluence and energy, or else by means of an instrument whose response is modified so that under specified radiation geometries the meter reading gives an approximate estimate of the dose delivered by all neutrons irrespective of energy.

The CEGB has a range of equipment for producing electromagnetic radiation and neutrons. Electromagnetic radiation is produced by sealed radioactive sources and by X-ray sets whose beams can be filtered to give narrow spectra. Neutrons are produced by a range of sealed sources, and by the $\mathrm{D}(\mathrm{d}, \mathrm{n}) \mathrm{He}$ and $\mathrm{T}(\mathrm{d}, \mathrm{n}) \mathrm{He}$ reactions. Thermal neutrons are available by moderating the $2.5 \mathrm{MeV}$ beam produced by the first of these reactions.

Experience with the facility has shown that many instruments have undesirable features which would have been impossible to identify without comprehensive radiological investigation. Some instruments, for instance, fall back to less than full scale at very high intensities, and some neutron instruments respond to gamma radiation of high intensity or high photon energy. Manufacturers sometimes introduce design changes with serious radiological consequences, and even the best instruments seem to develop faulty characteristics during their lifetime. But, apart from the need to identify faults, the principal task of the facility is to adjust instruments so that their scales read as accurately as possible, and to ensure that the user has all the information needed to interpret the scale reading correctly.

\section{Safety Testing}

THE collapse of the North Sea drilling rig Sea Gem and the cause of the Michael Colliery fire were two of the more spectacular investigations undertaken by the Safety in Mines Research Establishment during 1967, but the work of the establishment, under the Ministry of Power, covers every safety problem in the mines, including breathing appliances, methods of detecting mine gases and both gas and dust explosions. The work of the SMRE, under H. T. Ramsey, the director, is reported in the 1967 annual report (HMSO, 8s. 6d.).

Because of the SMRE's research in metallurgy and fatigue strengths, the establishment was asked to examine tie bars from the Sea Gem after it sank, killing 13 men. The bars were found to have been flame-cut from mild steel plate, which produced brittle areas under the cut surfaces. Some of the flame grooves had been filled with weld metal which extended the brittle areas. The results presented to the public inquiry concluded that "failure of tie bars ... was the most probable prime cause of the collapse".

The fire at Michael Colliery caused the death of nine men and was one of the most serious in recent years. Although it was impossible to investigate the site, the fire is known to have spread rapidly, and the section of roadway first affected was lined with polyurethane foam to reduce the emission of fire-damp into the roadway and the leakage of air out of the roadway into the waste. Further investigations have shown that, even though the foam contains a flame-retarding agent, it is still potentially highly flammable and needs to be covered with an incombustible coating such as asbestos cement.
Other preventive work at the establishment included studies of various types of self-rescuers which are to be adopted generally by the National Coal Board. Models produced in Germany have been fitted with a heat exchanger which keeps the temperature of the inspired air within a tolerable range, a great improvement over previous devices. More work needs to be done, however, on reducing breathing resistance and allowing for the presence of dense smoke. Improvements have also been made in techniques for measuring airborne dust by light-scattering methods, and a laser system has been developed that can measure both particle concentration and size distribution in a dusty atmosphere.

\section{Green Light for Reform}

AT last the administrative structure of the National Health Service may get the shake-up which most people agree it badly needs. At least, in a Green Paper published last week, Mr Kenneth Robinson, the Minister of Health, has set out briefly but clearly some reforms (National Health Service: The Administrative Structure of the Medical and Related Services in England and Wales, HMSO, 3s. 6d.). Everybody will be interested to see how well his kites fly.

The main theme of the paper is that the functions of the present hierarchy of committees-involving executive councils, regional hospital boards and boards of governors with their hospital management committees-should be replaced by a single authority in each area and that area authorities should be responsible for some important functions which are now in the hands of the local authorities. The present tripartito system is generally criticized for failing to provide the necessary coordination between the numerous services, and few tears are likely to be shed over its disappearance.

Mr Robinson envisages the whole new set-up as consisting of some 40 to 50 area health boards, each covering a large area and "having full scope for tho efficient and imaginative development of comprehensive services". These services would include various hospital and specialist services; community and local health services; general medical and dental practice, and the ophthalmic and pharmaceutical services as well as clinical teaching, postgraduate medical education and specialized services. Public health services would also be drawn into the general scheme. Each area board would have fifteen or sixteen board members, but the actual running and organization of services would be carried out by an exccutive formed by the senior officials of the five departments constituting each area board. One particularly welcome proposal is that the present largely lay administrative staff should be replaced by people with a broad professional knowledge of medical and related services. In areas with medical schools one or two additional members might be appointed to the boards on the nomination of universities. $\mathrm{Mr}$ Robinson maintains that central Government would retain its "guiding role", but that the area boards would on the whole be allowed to manage their own affairs without interference. The function of the Minister of Health would be to lay down general principles and to secure the coordination of services administered by the separate area boards. Mr Robinson's statement that such a transfer of re- 
sponsibility will not have any appreciable effect on the level of health and welfare services taken as a whole is, perhaps, over-optimistic. Furthermore, if the proposals are accepted, this would seem to be a good opportunity for working out some system of payment for board members instead of relying on their good will, sense of duty and any other motives.

So far the Green Paper is simply a basis for discussion and should be considered in the light of the recommendations of the Seebohm Committee regarding effective family service and of the Royal Commission on Local Government in England (due later this year). It is nevertheless a definite step forward and will be well received. Such dissatisfaction as there may be is likely to come from the medical officers of health who-according to Dr David I. Williams, Dean of King's Cross Hospital Medical School-will be affected most by the proposals. It seems that they stand to lose a large measure of the autonomy which they now enjoy, and may not be appeased by the Minister's "peace offering" of a senior position on an area board as principal adviser on all medical professional matters and director of the "planning and operation of services department".

\section{Astronomy is Fun}

THE Astronomy, Space and Radio Board of the Science Research Council must be worried that some of its more ambitious plans may go the same way as those of the Nuclear Physics Board-the $300 \mathrm{GeV}$ machine, for example. Perhaps this is why the Science Research Council has just published a report containing a lively review of the scientific interests of the Astronomy, Space and Radio Board which leaves no doubt about the excitement of the board's activities. The review, written by Professor P. A. Sheppard and Professor Fred Hoyle, makes up the larger part of the report and gives an insight into British astronomy and space research as it is in 1968 as well as an indication of the directions it may take in the near future. It was written as an introduction to the Astronomy, Space and Radio Board's statement of its policy and programme which, together with reports from the Science Research Council's two other boards, forms the basis of planning for what the council calls its Five-Year Forward Look.

The board-responsible for astronomy and space research in Britain and for radio work in this fieldis well aware that implementation of its plans depends on the financial resources available to the Science Research Council. Its members must be hoping that the fascination of the recent developments in astronomy and space research, brought out well in the scientific review, will be a convincing argument for their cause. It looks as though astronomers and space scientists, at least, have realized the importance of skilled public relations-something British nuclear physicists have not yet grasped. While few people know what the $300 \mathrm{GeV}$ accelerator is expected to do, the Astronomy, Space and Radio Board is trying hard to convey an impression of the vistas now opening in astronomy and space science, and the opportunities which will be missed if promising lines of research are not followed up. The report comes back to earth for the benefit of those still not convinced to point out the value to industry of postgraduates trained in space research, which involves advanced technology and close collaboration with industry.

The authors of the report are careful not to be too ambitious or even costly in their plans. They even give one example of an offer from NASA to fly an experiment for a group from Oxford and Reading Universities on one of the Apollo series being turned down for lack of money. The board gives several other examples of areas where it may not be able to do all that it hoped, and it is rightly worried about the scientific return from participation in ESRO.

Just as the nuclear physicists were concerned about the proportion of their budget which would have gone on the European $300 \mathrm{GeV}$ machine, the Astronomy, Space and Radio Board is not happy about the share of its financial cake swallowed by ESRO, currently running at around 50 per cent. The board sets its face against a further unbalancing of the expenditure by increasing the proportion going to space research or the proportion within the space research budget going to ESRO rather than to the national space programme. So far as ESRO is concerned, the object should be to provide facilities which are beyond the scope of individual European states. Now that the only large scale project to be seriously tackled by ESRO - the Large Astronomical Satellite-has been cancelled, much of the British scientific case for participation has gone, in any case. The report points out that attempts are now being made by Britain and other member states of ESRO to revive the TD-I and TD-2 programme. These two satellites were designed for investigation of the Sun towards the maximum of the solar cycle, and in the opinion of the board are sophisticated enough to go some way towards justifying ESRO's case. The plan seems to be to keep one of the satellites, either in the ESRO programme or as a separate project to be financed by the states still interested, at present numbering perhaps eight out of a possible ten.

If it turns out that the TD satellites are, after all, cancelled, ESRO's programme will be of the same quality as that of some of the European national programmes even if greater in quantity. The scientific return will be much reduced, and the case for British withdrawal will be even stronger, although there is no need for a decision just yet; the earliest date Britain can withdraw is the end of 1971 (notice must be given before 1970). The advantage of an earlier decision, however, is that it removes uncertainties about what launchers are going to be available to British scientists in the future; as far as the board is concerned, the alternatives to ESRO are increased collaboration with NASA and building on the Black Arrow launcher programme.

Just now, the board is concentrating on a successor to the UK 3 satellite (now Aeriel 3) launched from the United States in May last year. A decision on this has been hanging fire for more than a year, but the ESRO crisis has helped to settle matters and it seems likely that agreement has now been reached-at a Washington meeting last month-for two more satellites in cooperation with the Americans. In the past, cooperation with the Americans has proved not only smooth but fruitful and cheap. Because NASA provides satellite launchings free, research is actually cheaper by this means than if Britain used her own rockets. American reaction at the recent meeting 